\title{
Rare Book and Special Collections in Overview: Producing a National Directory
}

Describing library collections by location is nothing new. In the mid-nineteenth century, Luther Farnham published A Glance at Private Libraries, about libraries in the Boston area of the United States. Reginald Arthur Rye produced his highly praised Students' Guide to the Libraries of London in England just over fifty years later. ${ }^{1}$ That we, no less than our forebears, value such discovery tools collocating collections is evident from their continued publication, whether in print or, more recently, electronic form. National, annual library directories still produced include The American Library Directory. In Britain, the Chartered Institute of Library and Information Professionals (CILIP)'s Libraries and Information Services in the United Kingdom and the Republic of Ireland, a list of libraries by sector with contact details, remains available.

Yet up-to-date, all-encompassing national directories targeting special collections are uncommon. Most countries seem not to have tackled a national special collections census at all. Of the exceptions, America's extensive Subject Collections, originally published in 1958, arranging and describing collections in subject order by Library of Congress Subject Headings, was last issued in 1993. ${ }^{2}$ There remains the Directory of Rare Book and Special Collections in the United Kingdom and Republic of Ireland. First published by the Rare Books Group of the Library Association in 1985, this reached its third edition under the aegis of what had become CILIP's

1. Luther Farnham, A Glance at Private Libraries (Boston: Crocker and Brewster, 1855); Reginald Arthur Rye, Students' Guide to the Libraries of London (London: University of London, 1908). Praise for the latter includes: "Probably it has been a revelation to most of us that so many non-municipal libraries exist to which access is allowed on fairly liberal terms"; and: "Perhaps Mr. Rye's handbook may lead to a belated recognition of the immense resources existing among the numerous libraries of London, and to some movement for co-ordination..." E.A. Baker, "A Guide to the Libraries of London," Library Association Record 10, no. 6 (1908): 257-58.

2. Lee Ash and William G. Miller, with the collaboration of Barry Scott, Kathleen Vickery, and Beverley McDonough, eds., Subject Collections: A Guide to Special Book Collections and Subject Emphases as Reported by University, College, Public, and Special Libraries and Museums in the United States and Canada, 2 vols., 7th ed. (New Providence, N.J. : R.R. Bowker, 1993). The American Library Directory names special collections but does not describe them (see American Library Directory Online, www.americanlibrarydirectory.com/).

๑ 2018 by Karen Attar (CC BY-NC [https://creativecommons.org/licenses/by-nc/4.0/]). 
Rare Books and Special Collections Group in 2016. ${ }^{3}$ This article discusses some issues encountered in publishing the third edition. It hopes thereby to assist colleagues who may contemplate such a venture in an age in which special collections are becoming increasingly important as a status symbol and for public engagement as well as for research—but also at a time when print reference material and directories are becoming increasingly obsolete.

\section{Content and Purpose}

The Directory of Rare Book and Special Collections in the United Kingdom and Republic of Ireland (henceforward Directory) describes in 535 pages the rare book and printed special collections holdings of 873 institutions with at least fifty items across the British Isles. Repositories cover national, university, school, public, subscription, ecclesiastical, professional, club, and company libraries; libraries in stately homes, museums, and archives; and even a prison and a palace. Each library is listed as a single entity. Arrangement of the entries is geographical, with separate alphabetical indexes for library names, collectors, and subjects.

The Directory's purposes are:

- to provide a national overview of rare book and special collections across sectors, especially valuable for the many without a web presence; and

- to direct researchers of all levels to the most relevant libraries for their research needs, answering such questions as where they can best find clusters of books from a given time period on a given subject-in the wording of the first edition, 'to bring to the notice of scholars and researchers the location of rare book collections .... and to provide such information about their nature, size and importance as will enable them to assess whether or not further investigation is likely to be to their benefit." ${ }^{4}$

The emphasis is on the current whereabouts of collections available either routinely or as a last resort. Collections in private hands or in institutions that will not admit non-members are therefore excluded. The Directory is intended neither as a substitute for a catalogue, listing individual titles, nor as a policing tool to track the movement of collections, covered competently elsewhere. ${ }^{5}$

3. Moelwyn I. Williams, ed., A Directory of Rare Book and Special Collections in the United Kingdom and Republic of Ireland (London: Library Association, 1985); B.C. Bloomfield, with the assistance of Karen Potts, ed., A Directory of Rare Book and Special Collections in the United Kingdom and Republic of Ireland, 2nd ed. (London: Library Association, 1997); Karen Attar, ed., Directory of Rare Book and Special Collections in the United Kingdom and Republic of Ireland, 3rd ed. (London: Facet Publishing, 2016). Within the British Isles, Ireland has an electronic directory, RASCAL (Research And Special Collections Available Locally), available at www.rascal.ac.uk.

4. Williams, ix.

5. Descriptions of sales, dispersals, and acquisitions typically appear in the quarterly journal The Book Collector and sometimes in the triannual Bulletin of the Historic Libraries Forum (see www.historiclibrariesforum.org.uk/hlf/publications.html), with summaries in the chapter "Rare Books and Historical Bibliography" in the serial British Library and Information Work, published at five-yearly intervals. 


\section{Why Print?}

Like Subject Collections, previous editions of the Directory were published before the advent of the Internet and in its infancy respectively. Correspondence was by post. The third edition could not have been produced without the Internet and is affected by the Internet. E-mail communication sped up the production process and rendered the financial outlay for the project minimal. The only major cost was indexing. ${ }^{6}$ The World Wide Web helped to establish the status of collections listed in the previous edition that no longer existed in the same place and to check details from OPACs and from digitized books. Most obviously, the earlier editions, given the time of their production, had to be all-sufficient entities, including information about the repositories as well as about the collections. By contrast, the third edition, appearing in an electronic age, is a portal. It provides uniform resource locators and expects users to follow them to obtain greater detail both about the content of specific collections where available and practicalities surrounding their consultation and use, such as the service hours and rules about making reproductions (both liable to change).

"Why print?" is an obvious question, with the implication "Why not opt for an online publication in the first place?" The query may be particularly pertinent in the United States, where the printed directory of special collections was last printed before the Internet age and the major current directory is online. A pragmatic reason for us was that an electronic tool, beyond an e-book, was not an option: a printed volume is what Facet Publishing, CILIP's publishing arm, could offer, so that the choice was between a printed update and no update at all. Of these alternatives, a printed update was deemed preferable. I was appointed editor for the new edition.

To judge possible demand for a printed directory in an electronic age, I asked via various e-mail lists whether librarians thought their institutions might purchase such a book for a guesstimated price of between 75 and 100 pounds (\$US 114-152 at the time of asking). ${ }^{7}$ The targeted listservers included general and specific British e-mail lists; lists targeted at the American and European rare book communities; and, most broadly, the IFLA Rare Books and Manuscripts Section. Almost eighty libraries responded affirmatively, mostly from the United Kingdom but also from the United States, Canada, Australia, Belgium, Germany, Italy, and Switzerland, and CILIP felt that the response justified proceeding with the project. The price named

6. Telephone calls could have added to the budget; callers generously chose not to claim. Cf the second edition, which received a grant from the Leverhulme Trust for the work of revision, travel, computing, and secretarial costs (Bloomfield, xv).

7. The lists were: lis-rarebooks@jiscmail.ac.uk; lis-libhist@jiscmail.ac.uk; archives-nra@jiscmail. ac.uk (British lists for rare books, library history, and archives respectively); lis-link@jiscmail.ac.uk (a general British library list); dcrm-1@lib.byu.edu (America); members of the Consortium of European Research Libraries (www.cerl.org). For the IFLA Rare Books and Manuscripts Section, see www.ifla. org/rare-books-and-special-collections. 
in the query turned out to be a wild underestimate, but brisk sales, far exceeding the publisher's expectation, subsequently proved the genuineness of the desire.

Criticism of a printed reference tool was that it dates quickly and is slow and expensive to update. ${ }^{8}$ True as this is, the implication that a database will necessarily be current, merely because updating is technically easy, is erroneous. Human and financial resources are needed to maintain it, just as they are needed to create the printed volume. Updates to databases created through project funding may cease when funding does, as for a database of printed special collections within the greater London area of England. ${ }^{9}$ An alternative wiki-based system allowing repositories to update their own entries would founder from ignorance and lack of time, to judge from the difficulty of eliciting entries for the 2016 edition of the Directory and from the lack of awareness of some contributing institutions about what the Directory was. While major libraries whose holdings were already well known might keep their entries up to date, other repositories would fall behind. The printed volume is, in a way, more open because its limitations are apparent, whereas assumptions and expectations of currency are greater for an electronic source. Curiously, that a printed volume is a slower and less flexible search tool than a database enabling Boolean searching was not an instant reaction.

The stasis of print can work in its favour. A review complained: "Internet links are ephemeral and dependent on those who host them; this printed book gives us some guarantee of permanence." ${ }^{10}$ Redesigning a website can mean losing information about collections, especially if a new website is geared more toward marketing than academic helpfulness. The web overseers in one major library wanted to repurpose the website to emphasize income-generating factors. Believing that users did not need to know about collections when individual items could be discovered by the catalogue, they directed curators to reduce the information about the library's collections drastically. This change of emphasis was said to be symptomatic for the sector.

A major benefit of print is the statement it makes about the value of special collections. In this respect, a directory is comparable with a "library treasures" volume. Both work to raise library profiles, the one at collection level, the other at item level. Although we commonly advertise individual treasures on our websites, the desire for treasures volumes is booming on both sides of the Atlantic, with books

8. In a form of damage limitation, I tried to maximize currency by keeping the period between the receipt of entries and submission as short as possible and by sending out a request via the major e-mail lists in January 2015 for updates on entries (an appeal that elicited some response).

9. See, for example, MASC25: Mapping Access to Special Collections in the London Region, last updated in 2007: www.masc25.ac.uk.

10. William Baker, Times Literary Supplement, 9 June 2017. 
about the Morgan Library and the Huntingdon Library in America no less than for the British Library and the National Library of Scotland alongside smaller libraries in the United Kingdom. ${ }^{11}$ Reviewing the 2007 treasures volume for Durham University Library, David Pearson questioned the purpose and audience of such volumes in an Internet era. He concluded: "There is nothing wrong with that tactic [referring customers to the website], but the paper documents are impressive and definitive in their corporeality"; a point made generically in the United States by Sidney E. Berger. ${ }^{12}$ A printed directory of special collections declares the worth of special collections broadly. Furthermore, library users new to the subject may find a printed book as a tangible object included in library catalogues and visible on library shelves. Locating a database that one does not know exists can depend more heavily on serendipity or the intervention of a reference librarian.

An argument for print was that it provides a snapshot of conditions at a given time. More positively, the ability to compare the third edition of the Directory with the second instantly substantiates points made briefly in the introduction and in the quinquennial overviews of British librarianship (see note 5) about trends in collection movement, such as the movement of collections from public libraries (victims of an age of austerity) to academic or national libraries in a centralization of collections or indeed to archives (some collections have also been dispersed). It contributes to library history by indicating the growth not only of the number of special collections but of particular libraries: one new university, Oxford Brookes University, progressed from having one special collection in 1997 to 27 in 2016, all concentrating on material from the nineteenth to the twenty-first centuries. None of this is apparent from an evolving database, which by its nature hides its history.

Furthermore, the browsability of print raises awareness of all sorts of collections for which one might not think to search. This applies partly to collections within repositories: who would have expected a Wizard of $\mathrm{O} z$ collection (Reading University) or "Miss Great Britain contest" (Morecambe Library, a public library)? It also applies to the lesser-known repositories themselves, or repositories such as archives and art galleries where one might not expect to find rare books or special collections.

Print and online editions have complementary benefits. An aim for the third edition, beyond the comprehensive nature and accuracy for which its predecessors

11. The Morgan Library: An American Masterpiece (New York: Pierpont Morgan Library, 2000); Director and curators, The Huntington Library: Treasures from Ten Centuries (San Marino, Calif.: Huntington Library, 2004); Philip Howard, The British Library: A Treasure House of Knowledge (London: Scala, 2008); Iain Gordon Brown, Rax Me That Buik: Highlights from the Collections of the National Library of Scotland (London: Scala, 2010).

12. David Pearson, "Treasures of Durham University Library [review]," The Book Collector, 58: 138; Sidney E. Berger, Rare Books and Special Collections (Chicago: American Library Association, 2014), 345-46. 
also strived, was adaptability. I requested information in a formulaic way, partly to help researchers to compare collections, but also in the hope that the content could be transferred, should funding become available, to an additional, fully searchable Boolean database. Representation by both means would be ideal.

\section{Method}

The project began with ten graduate trainees from the University of Oxford looking up e-mail addresses for the institutions represented in the previous edition of the Directory. ${ }^{13}$ I then e-mailed these institutions in groups asking them to update their entries, attaching the relevant section of the 1997 Directory and a style sheet. To raise the venture's profile and to demonstrate its validity, CILIP Update, the monthly newsletter sent to all 1,300 or so CILIP members, published a three-page article almost immediately afterwards describing what the new edition of the Directory was, what it did, and why it was necessary. It referred to the requests just made and appealed to readers to spread news of the project, especially to colleagues who might be outside standard library networks, and to send entries. In the entry-gathering phase, I maintained a blog, with weekly posts by both volunteers and me, to raise the project's profile further and encourage participation. ${ }^{14}$

I undertook a multipronged effort to reach relevant repositories not represented in the previous edition, with advertisements via the same general and specific British lists that I had used to ascertain demand for the Directory (see note 7), CILIP's umbrella e-mail communications system with all members, and through relevant CILIP special interest groups, such as schools and local studies. Related heritage bodies, the Historic Libraries Forum (which netted the Cathedrals Library Association), the Archives and Records Association, and the Museums Association, placed requests for entries in their newsletters. Requests regularly asked recipients to pass the message on to staff of relevant libraries who might not belong to professional networks. A volunteer listed all museums in the Museums and Galleries Yearbook that stated they had special collections of printed books, and I approached them. ${ }^{15} \mathrm{~A}$ few libraries had notified me of their existence when I asked about the demand for a third edition. Colleagues told me about others, and one, Chawton House (a new

13. We targeted library trainees for the purpose of giving them additional practical experience necessary to gain places at library schools and beneficial for demonstrating professional commitment at the outset of their careers; as an additional incentive, each trainee gained an additional potential referee for the next stage of his or her career (although ultimately nobody approached me for a reference). We sought the volunteers from Oxford because Oxford employs annually about fifteen graduate trainees in a networked program, so there was a large pool of candidates. Moreover, it has a high proportion of libraries containing rare books, and we hoped that some of the trainees would be interested in them, possibly even attracted to Oxford because of them.

14. Directory of Rare Book and Special Collections in the UK and Republic of Ireland, https:// specialcollectionsdirectory.wordpress.com.

15. Katie Dawson, ed., Museums and Galleries Yearbook 2013 (London: Museums Association, 2013). 
library for the study of English women's writing from 1600 to 1830), had featured in library literature: ${ }^{16} \mathrm{I}$ contacted them individually.

The request for entries included a detailed style sheet, which was also mounted on the Directory blog, and, for contributors who might not want to read seven pages of instructions, an annotated sample entry as a summary. I requested an address, URL, telephone number, generic e-mail address, with a brief paragraph describing the formation of the library, its purpose if not self-evident, the nature of the special collections, and up to fifty words for each named special collection of at least fifty titles. This description was to note the quantity of items contained therein, the subject matter, the date range, the language(s) if not predominantly English, other salient features (such as "many in contemporary bindings"; "several heavily annotated"), and the immediate provenance. In a drive for greater precision than in earlier editions, I asked libraries to provide date ranges rather than terminal dates, such as " 100 books $1580-1820$, mainly 18 th cent" rather than: " 100 books pre1850 "; to avoid evaluative statements such as "A superb collection" (the descriptions would allow readers to assess excellence for themselves); and to give the size of collections rather than using relative adjectives such as "large" or "small." I further asked libraries to list relevant publications about the collections and to flag collections not catalogued online and state the type of finding aid for them.

Inevitably, considerable chasing for entries was required, ${ }^{17}$ taking the form of further bulk e-mails; an individual e-mail to each known outstanding library, including the text of that library's previous entry in the body of the e-mail; pursuit by local colleagues in places with high concentrations of special collections, such that a known body added weight to the request of an impersonal editor; and telephone calls by volunteers, followed up by further individual e-mails. Just before the final deadline, I published a list on the Directory blog of outstanding repositories and advertised its presence. This galvanized a few responses.

Over one hundred repositories still failed to respond, mainly public and school libraries. The 1997 Directory had carried over entries from the previous edition for unresponsive libraries. ${ }^{18}$ Some inaccuracies even at the time of publication had resulted, such that a company library in London stated when submitting its entry for the third edition: "The details of the previous entry are over 30 years out of date-we moved from the Park Street address in 1983." Following the same policy

16. Helen Scott, “Jane Austen's Text in Context,” Library + information Update 3, no. 3 (2004): 28-31.

17. Cf Bloomfield, $x$, recording about the latter that, after a letter and two reminders, "a substantial number of libraries still did not reply." Lee Ash also refers to unreturned questionnaires in the American context (Lee Ash and William G. Miller, eds., Subject Collections: A Guide to Special Book Collections..., 2 vols., 6th ed. (New York and London: Bowker, 1985), ix.

18. A practice also followed in Ash and Miller, Subject Libraries, 6th ed., with typographical highlighting (see vii). 
of inclusion after almost twenty years would have impaired currency and, hence, usefulness. Much had changed, and it was generally impossible to know what was happening when libraries did not respond and lacked a web presence: ${ }^{19}$ some late respondents informed me that they had ignored previous e-mails because nothing had changed since 1997, and others said that they had not replied because they no longer had a library. We therefore listed the 116 unresponsive libraries in an appendix of libraries that were recorded as holding special collections in the 1997 Directory and for which no information was available for the third edition. Individual e-mails informed all such repositories of this plan. If the project could elicit no information after multiple requests, it seemed unlikely that researchers would either. At the same time, we wanted to place a marker both for researchers and for the editor of the next edition of the Directory. Some entries in the 1997 Directory had stated that the rare books were elsewhere; these headings were removed for the 2016 edition. A few libraries with entries in the 1997 Directory requested to be removed in 2016, preferring their collections to be restricted to member use or discovering fears about security.

Many entries required considerable editing, either to remove unwanted information (for example, about a café on the premises), or to rearrange information, especially to state the immediate source of acquisition after, rather than before, the essence of a collection. Some submissions from responding libraries stated: "The same as last time" when internal evidence suggested otherwise (for example, "the library is currently (1980) being classified"). Imprecise or lacking information necessitated many follow-up queries. Not all libraries replied. Ultimately, policy was that an incomplete entry, at the very least flagging the existence of a repository, was better than none.

As libraries were arranged geographically by town within country, indexing was essential to trace particular libraries and subjects. The second edition of the Directory had contained a single index. The third edition had three, which proved to be far clearer: of libraries (for which I marked up the names of libraries typographically before submission), of subjects, and of collectors.

\section{Results}

The project resulted in entries for 873 repositories. Importantly, it gathered collections together, including uncatalogued collections, and collections without a virtual profile, such as those in churches, businesses, London livery companies, clubs, and schools. For those of us in larger libraries who might take a web presence for granted, the frequency of its lack was a salutary shock. As an example of the value

19. There were occasional exceptions. Two collections were known to be in limbo but the future location was unknown, and we flagged this status. 
of a directory, a google search for "Aldine collection" instantly brings up on its first page the 1,500-item strong collection at the John Rylands Library in Manchester, together with collections in America at Stanford, the University of California (the Ahmanson-Murphy Aldine Collection), Los Angeles, the University of Texas, and, in British Columbia in Canada, the Simon Fraser University. It does not include collections in which Aldines are described as a notable element, but which are not exclusively Aldine (for example, at Trinity College Cambridge or at the stately homes Blickling Hall and Kedleston Hall), nor the admittedly much smaller Bigg collection of Aldines held at Harrow School (an independent boys' school in London): the school's library does not feature on its website at all, so that a search for Aldine and Harrow yields no results.

Ultimately the Directory included almost one hundred new institutions. Some 39 of these were National Trust properties, whose libraries had benefited greatly from the appointment of a Libraries Curator for the Trust in 1999. The new libraries and collections represented a mixture of antiquarian and modern material. Libraries with previous entries recorded new collections, either newly acquired or previously unreported. Some deaccessioning had also taken place. Since publication, I have been made aware of the existence of another six libraries, and the new destination of a library in the appendix has become known.

Government and hospital libraries had largely disappeared in the period between editions. Entire institutions had merged. Several institutions that still existed no longer held rare books. The general result was a centralization of collections in fewer, larger repositories. Some migrated collections remained readily identifiable: for example, two parish libraries previously at Loughborough University moved to Nottingham University in 2013, where they remain as discrete special collections and are described, with a note about their immediate acquisition. Others have lost their distinctive identity, such as the Punch archive, sold from the Punch office to the British Library in 2004 and subsumed within the latter's collections.

By submitting entries to the Directory, libraries found out about their own collections. The librarian of one Oxford college reported having asked the Oxford University cataloguing team to analyze the dates of books in the Fellows' Library for the project, in a blog post that resulted in the university's cataloguing team being inundated with similar requests by other colleges. ${ }^{20}$ Errors on websites emerged and were corrected, as I on occasion looked at websites, noticed discrepancies between information there and the information sent to me, and queried the difference.

20. Owen McKnight, "Counting Books," 16 Apr. 2014, https:/ / specialcollectionsdirectory.wordpress. com/2014/04/16/ counting-books/, simultaneously published on the Jesus College Libraries blog, https://jesuslibraries.wordpress.com/2014/04/16/counting-books/. 
As a side effect, the Directory revealed such circumstances concerning the state of special collections nationally as a sobering number of reorganizations and severe understaffing. As we asked institutions whether their catalogues were online and, if not, how collections were catalogued, the Directory revealed the extent of hidden collections better than a "Hidden collections" survey, based on a smaller number of libraries, could do. ${ }^{21}$ By exposing hidden collections, it could be used to direct volunteers to projects.

Communication concerning the Directory exposed the need for more training to help general librarians who had gained responsibility for special collections willynilly: one librarian in charge of early printed books had not heard of the STC, while another talked of collections having "one incunabula." It showed that perceptions widespread in research libraries about the importance of the copy-specific, fueled by burgeoning academic interest in the history of reading and in material culture, have not percolated through the entire rare-book-owning community. One college library, for example, holds books from the library of the dilettante and amateur architect Charles Kelsall (1782-1857), with annotations including records of acquisition and sometimes earlier provenance; the college had to be encouraged to report the collection to the new edition of the Directory, with an explanation of the value of books beyond their texts. Neither was everybody aware that researchers may think in terms of collections beyond single libraries. A few libraries responded to the request for an entry with the message that information about their collections was on their website-which, while true, did not enable researchers to link from those collections to others with similar holdings relevant for their needs. Finally, it emerged that the "unique and distinctive" element of special collections that motivates some libraries makes others shy, as they say that they have nothing that cannot easily be found elsewhere-the statement "we have nothing that is not in the British Library" came up a few times. The notion that special collections are a status symbol and the jewel in the collection crown was no truism, as the sheer quantity of unresponsive libraries demonstrated. Moving from, for example, public libraries to academic libraries or archives implies that special collections can even be a burden. Greater centralization can be predicted.

The Directory helped libraries to map their collections, showing how they fit into a "unique and distinctive" model; to pitch their collections and to see what is special; and to locate other libraries with which to collaborate for digitization and other projects. The assistance could extend beyond libraries: in my institution, the Development Office used the Directory to see how many libraries within a certain radius

21. Mike Mertens and Dunia García-Ontiveros, "Hidden Collections: Report of the Findings of the RLUK Retrospective Cataloguing Survey in Association with the London Library" (Research Libraries UK, 2012), www.rluk.ac.uk/wp-content/uploads/2014/02/RLUK-Hidden-Collections.pdf. This was based on 77 responses representing 75 separate institutions. 
held collections pertaining to Nazism when considering whether to bid to host a research institute.

The project showed that institutional obligations to answer e-mails often are not observed. More positively, it demonstrated the possibility of producing a substantial work on a low budget.

\section{Challenges and Evaluation}

Challenges when dealing with some thousand institutions were inevitable. That of netting entries has been discussed above. I should do certain administrative things differently if beginning the project again. For example, the dedicated e-mail address for the Directory to keep track of communications had the suffix "outlook.com" (a branch of hotmail); an institutional e-mail address would have been better for academic weight and proof of validity, and to minimize the possibility of servers treating mail from the Outlook address as spam. Further challenges, and ways of dealing with them, were:

Moves and Mergers. Relocation meant that some libraries received correct but apparently irrelevant portions of the Directory with their old entry: for example, the John Ruskin Library in Lancaster received the section of the 1997 Directory containing the Isle of Wight as its 1997 location. The sheer quantity of the project made working in bulk the most efficient way to start, and issues were resolved at the follow-up stage. But it was important to know how to apologize!

Reaching the Correct Recipient. I began with generic e-mail addresses, for rare book departments where they existed, for institutions generally otherwise. Not all emails reached their destinations: for example, not being forwarded by the visitor center of stately homes to the library. The telephone calls were invaluable in such circumstances. One large academic library sent a substandard update because the library assistant responsible for dealing with e-mails to the departmental inbox did not see fit to pass the request to a curator. Alerted to the deficient entry, the Head of Department delegated the task to a curator who redid the work superbly; I would now always target somebody higher rather than lower in the hierarchy from the outset.

Encouraging Contributions. Contributing to the Directory competed with multiple other demands on time, especially in understaffed libraries. Persuasion was essential. If redoing the project, I should increase it, reinforced with visits if necessary. 
Absent Libraries. Beyond approaching museums and learning of libraries from colleagues, attempts to gain entries from new libraries depended on the use of professional networks. But curators overseeing the missing collections, perhaps retired librarians or nonlibrarians, are not necessarily networked professionally. I could have tried to locate further repositories by working through general library directories, although whether the results would have justified the effort is questionable. ${ }^{22}$ On another occasion I would circulate the index of libraries widely and request the names of missing relevant libraries, possibly offering a prize for whoever could submit the most names. I would also target publishers for information about their printed archives.

Content. The greater precision requested concerning collections worked well. On another occasion I should ask libraries to state explicitly when collections have been digitized and how they are available (for example, "pre-1915 books digitized on 'Making of the Modern World' [subscription database]") and to say when collections are supported by archival material, such as a former owner's invoices or manuscript catalogue.

Accuracy. Another challenge is the necessity of relying on what libraries say about themselves. Some admit to knowing little about their collections. Others may talk themselves up, as an e-mail from an academic library at the beginning of the project underlined:

This is just to let you know that will make a brief submission for the new directory. I just took a look at the old one and fell about laughing because it's really a tissue of lies to make us look like some worthy academic library! The Joe Bloggs [name changed] bequest was large but the items, although they had book plates, were not even identified in the accessions register or the catalogue and were simply added to stock at the appropriate place and were almost all weeded as they disintegrated. $[\mathrm{A}]$ and $[\mathrm{B}]$ nobody has ever heard of.... The $[\mathrm{C}],[\mathrm{D}]$ and $[\mathrm{E}]$ bequests all... sat in the closed access store until about 2005 uncatalogued. About half the material was 1950s and 60s popular paperbacks falling apart or material duplicated in the collections. Those retained were added to the catalogue ... most of [D] was sold. It just makes me wonder about the reliability of other entries. Mind you, it has to be said that the person who I am sure compiled the entry was a fearful academic snob! So you will get a more limited but more useful entry shortly.

22. Lin Franklin and June York, eds., Libraries and Information Services in the United Kingdom and Republic of Ireland 2009-2010, 36th ed. (London: Facet Publishing, 2009); Sheila Garrard, ed., ASLIB Directory of Information Sources in the United Kingdom, 16th ed. (London: Routledge, 2010). The former lists more than 2,200 libraries, with no detail about their content. The latter, 1,294 pages of small print in three columns, provides some detail. Neither was entirely comprehensive for Directory purposes. 
Inconsistency. The previous edition had stated the quantity of pre-1701 English-language books and British imprints in traditional terms of STC and Wing items. ${ }^{23}$ The ascendancy of ESTC to cover both publications, with its easy availability and greater detail, ${ }^{24}$ was thought to lessen reliance on, and even knowledge of, the printed shorttitle catalogues. Thus for the third edition I requested figures in terms of the century of publication. This had the added advantage of aligning the method of description with that used for foreign imprints. Not all libraries complied. Not all could: for example, if they did not have an electronic catalogue to interrogate. To align the Directory's cut-off date with the cut-off date for special collections in some major British libraries, including the British Library and the National Library of Scotland, I also requested information concerning the general quantity of books to 1900 , where the previous edition had ended at 1850 . This also proved difficult for libraries to provide. Ideal as consistency was for easy comparability, I quickly had to accept the unavoidabability of inconsistency for such a large venture.

Any tool to discover collections depends to an extent on administrative decisions by libraries, made perhaps centuries ago, about what to regard as special. One library's special collection may another library's general stock. Senate House Library (University of London), Liverpool University Library, and Trinity College Dublin all hold all editions and translations of the science fiction writer Terry Pratchett, but library administration results in his appearing in the Directory only for Senate House Library, which keeps the books in a dedicated Pratchett collection; in Liverpool the same books constitute part of a wider science fiction book collection, while at Trinity College Dublin they appear to be scattered. The emphasis on named special collections means that libraries that have dispersed their gifts and bequests receive less Directory space than libraries that have kept them together. This is an inherent flaw that must simply be accepted. The introductory paragraphs for libraries sought to mitigate it.

\section{Conclusion}

Producing a national directory of rare book and special collections is not to be taken lightly. It is time-consuming. It is humbling, insofar as the movement of collections will date the work quickly. It is frustrating, in that consistency, completeness, and perfection are unattainable. Such a project can be a self-perpetuating exercise, as the libraries that see the value of being included may well be the libraries that have well-developed web pages for their special collections, contribute to the British

23. A.W. Pollard and G.R. Redgrave, A Short-Title Catalogue of Books Printed in England, Scotland, and Ireland, and of English Books Printed Abroad 1475-1640, 2nd ed., W.A. Jackson, F.S. Ferguson and Katharine F. Pantzer, eds., 3 vols. (London: Bibliographical Society, 1976-91); Donald Wing, Short-Title Catalogue of Books Printed in England, Scotland, Ireland, Wales and British America, and of English Books Printed in Other Countries 1641-1700, 2nd ed., 3 vols. (New York: Modern Languages Association of America, 1982-98).

24. English Short Title Catalogue (http:/ / estc.bl.uk). 
academic union catalogue ${ }^{25}$ and are generally well-networked, while collections under the radar that need prominence fall behind.

Yet such directories are worthwhile. The section headed "Results" above states several benefits. Additionally, directories help the book trade and prospective donors to target the most appropriate repositories for their wares for intelligent collection development. Their existence demonstrates the importance of libraries as preservers of the cultural heritage. They show small libraries that they are not alone and where they might seek guidance. They guide the media to find "material culture" to commemorate historic events. The Directory's underlying purpose of directing scholars to relevant collections presupposes that scholars already have a research interest. They might not. The availability of raw material fuels research, and directories raise awareness of the material available to be mined, especially newly acquired collections and collections in unexpected places. In all of these, the professional goodwill evinced by all engaged in the compilation of a directory is a service profession's act of service to society.

For the British project, I experienced a vast amount of support and goodwill: from the CILIP Rare Books and Special Collections Group (the project owner); from CILIP more widely, through its publicity channels; from the national libraries and the Bodleian Library, whose full backing was an important additional sign of credibility; and from individuals who helped, alerting me to new libraries, and exhorting colleagues to contribute-including a wife who prodded her husband to send an entry. The resulting product is useful to researchers, librarians, the book trade, and others. Lessons and patterns learned are also valuable, with recognition of training and support needed, of the direction of special collections, and of the extent of hidden collections. If our experience can help colleagues in other countries, the project will prove of more use still.

25. Copac: http:// copac.jisc.ac.uk. The catalogue represents about ninety academic, national, and specialist library catalogues.

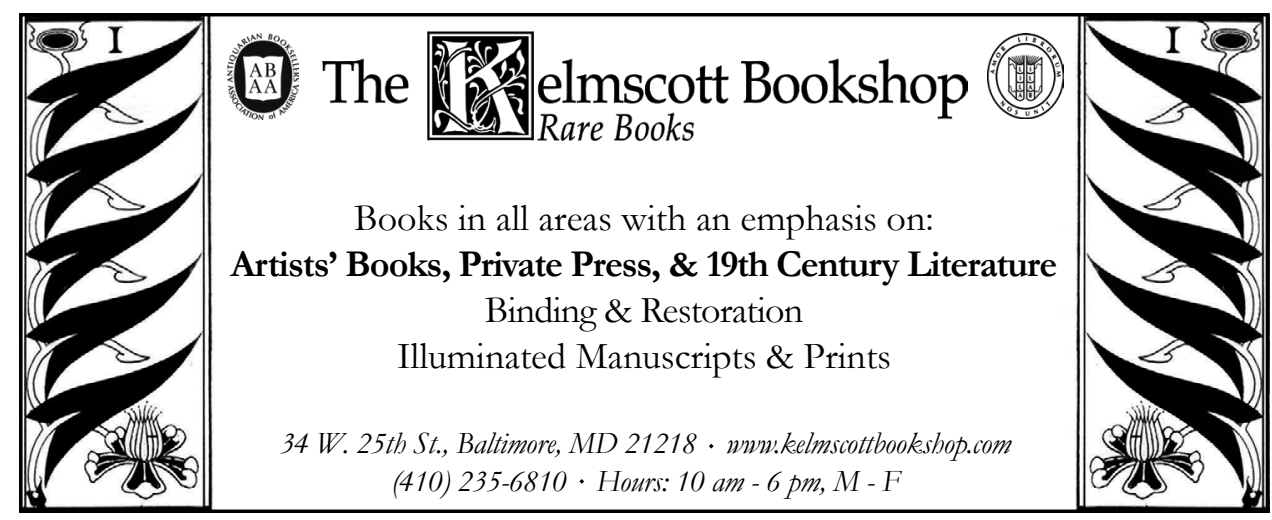

